\title{
Teaching power system stabilizer and proportional-integral- derivative impacts on transient condition in synchronous generator
}

\author{
Sugiarto Kadiman, Oni Yuliani, Trie Handayani \\ Study Program of Electrical Engineering, Institut Teknologi Nasional Yogyakarta, Indonesia
}

\begin{abstract}
Article Info
Article history:

Received Oct 12, 2020

Revised Mar 20, 2021

Accepted Jul 16, 2021

\section{Keywords:}

MATLAB/Simulink

PID controller

Power system stabilizer

Single machine infinite bus

Transient generator

ABSTRACT

Understanding the concepts based on problem solving is not an easy methodology in teaching the impact of power systems stabilizer (PSS) on transient synchronous generator using MATLAB capability. Experiments conducted in simulating sessions play an important role in this teaching. This simulation can simulate power system stability behavior with reasonable accuracy in less time. This transient phenomenon of a power system utilizing synchronous generator and modelling by fully three-phase model with changes in stator flux linkages neglected is analyzed by employed single machine infinite bus taken to the power system. Whereas a power system stabilizer which consist of a wash-out circuit, two stages of compensation, a filter unit, and a limiter, is applied to control voltage and frequency of power systems in transient condition. Proportional-integral-derivative (PID) controller tuned by Ziegler-Nichols's method is cascaded to conventional PSS in order to enhance the response time of system while providing a better result in damping for oscillation. This gives the clear idea about PSS and PID controller impacts on transient synchronous generator and its enhancement to the students of electrical engineering program, Institut Teknologi Nasional Yogyakarta.
\end{abstract}

This is an open access article under the CC BY-SA license.

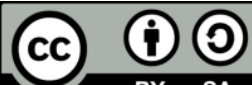

\section{Corresponding Author:}

Sugiarto Kadiman

Study Program of Electrical Engineering

Faculty of Industrial Technology

Institut Teknologi Nasional Yogyakarta

Jalan Babarsari, Caturtunggal, Depok, Sleman, DI. Yogyakarta, Indonesia

Email: sugiarto.kadiman@itny.ac.id

\section{INTRODUCTION}

Teaching the power systems stability concepts regarding transient synchronous generator becomes a challenge. This begins from the fact that the power systems must preserve voltage and frequency in the required level under any disturbances, mostly electromechanical low frequency oscillations (LFO) [1], [2]. Under transient conditions, the voltages or the currents are still significantly sinusoidal in shape, but the amplitude fluctuates with time and the signal may be shifted away from the zero line [3], [4]. These oscillations decrease power transfer capability and can trigger instability in the power system, which in the end can lead to failure of the power system [5]. The one of many methods to guarantee stability is to damp electromechanical oscillations by using generators' excitation or automatic voltage regulator (AVR) [6]. High gain excitation system in supplement with AVR will damp out the oscillations of low frequency with small amplitude. Another method is augmenting supplementary control loop to the input of the AVR and excitation system of synchronous generator called by the PSS or power system stabilizer [7]. PSS were 
introduced as a mean to boost damping through the modulation of synchronous generator's excitation so as to extend the power transfer limit. Input signals to the PSS may be proportional to angular rotor speed, generator output frequency or active power output. Indeed, the calculations involved in this power systems stability are very tiresome and complex.

Understanding the concepts based on problem solving is not an easy methodology in teaching transient stability of synchronous generator in power system. Experiment plays an important role in such power system stability teaching. It has to affiliate firmly with theory teaching. The entering of computer simulation to the teaching process has become an inevitable trend [8], [9]. This simulation which possible to simulate power system stability behavior with reasonable accuracy in less time, will become an interface between the theory teaching and experimental session. Many electrical engineering departments teach power system stability based on simulation, even for the laboratory studies, but some number of these simulationbased studies fail to give the comprehensive concept of the system. There are many non-linearities in power systems stability, especially in synchronous generator models. These non-linearities cannot be completely brought out by the simulation tools due to its difficulty in implementation and time consumed by the computers.

The non-linearities in power systems stability must be changed into a linearized model. Although modern control methods have been used to minimize the arranged objective function of power system stabilizer, namely fuzzy logic PSS [10] and adaptive fuzzy rule-based PSS [11], the conventional lead-lag structure of power system stabilizer is still chosen because of the ease to tune online. The reason behind that might be the ease to tune online and the lack of stability guarantee regarding to some methods of adaptive or variable structure [12]-[15]. Maintaining the best damping performance when there is an extreme change in system operating condition, an auto-tuning stabilizer of proportional-integral-derivative (PID) structure can overcome this problem. Many studies related to such structures have been carried out [16]-[18]. But, the PID parameters are still selected and optimized by adding various search algorithms, such as bacteria foraging, particle swarm optimization, and fuzzy logic controller. Those PID's structures still leave a problem, namely the controller's stability guarantee [19], [20]; On the contrary, the PID controller tuned by Ziegler-Nichols's method preserves the stability margin [21].

The simulator of conventional lead-lag model of PSS cascaded with PID controller for controlling power systems stability on transient synchronous generator has been developed and implemented in Electrical Engineering Program Study, Faculty of Industrial Technology, Institut Teknologi Nasional Yogyakarta. This simulator preserves the stability condition of PID structure tuned by Ziegler-Nichols's method.

This paper explains the way in which simulator of the power system stabilizer for stabilizing transient condition of synchronous generator is developed. Procedure for making instability problem and how the problem is to be corrected is demonstrated. Section 2 explains research method. Result and analysis are given in section 3 . The conclusion is drawn in section 4 .

\section{RESEARCH METHOD}

\subsection{Transient stability of synchronous generators in power systems}

In modern power system where a number of synchronous generators are operated in parallel, studies are usually achieved to confirm that the generators will operate appropriately in the event of possible faults or changes in system conditions. Studies concerned with transient stability of synchronous generator examine the ability of the generators to preserve synchronism from large oscillation formed by a transient disturbance. Because of a large oscillation, models of machines should describe the crucial nonlinearity in the frequency range between 1.0 and $5 \mathrm{~Hz}$ [22]. The dynamic behavior of synchronizing oscillation is influenced by system parameters and kind of control.

In a large power system, it is not practical to depict each and every component in full detail. Depending on the range of response frequency counted to be important for the problem at hand, proper model of the required fidelity would be selected. The electromechanical oscillation frequency of synchronous generator in power system lies between 0.5 to $3 \mathrm{~Hz}$. But, the transient time constant ranging from 0.5 to 10 seconds is usually longer than the period of the electromechanical oscillation.

To reduce the effort spent on establishing the model and on computation, the simplification that are obtainable by the separation in time scales of the different dynamic behaviors and that the harshness of a disturbance is usually attenuated as it propagates through the system; i.e., the duration of the electrical transient of the network is relative short to the electromechanical dynamic of synchronous generator. So, a static representation of the network can be used where longer electromechanical oscillation are primarily of interest. The models chosen for generators on the network need not be the same. Some understanding of 
basic dynamic behavior of synchronous generator in transient condition can be attained using a simple model of generator and network, known as single machine infinite bus.

The single machine infinite bus with neglected stator transient or stator $q d 0$ flux linkages is shown in Figure 1. If voltage drop across external line is $V_{z}=\left(r_{e}+j x_{e}\right) I$, using transient model then the equations of $d$-axis and q-axis winding voltages without contribution of the $k d$ and $k q$ damper windings will be changed; the parameters of linearized synchronous generator model is shown in Table 1 . The derived sets of linearized equations of the system are $\Delta V, \Delta E_{q}^{\prime}, \Delta E_{f}$, and $\Delta \delta$. Usually, small resistance of stator winding, $r_{s}$, is neglected.

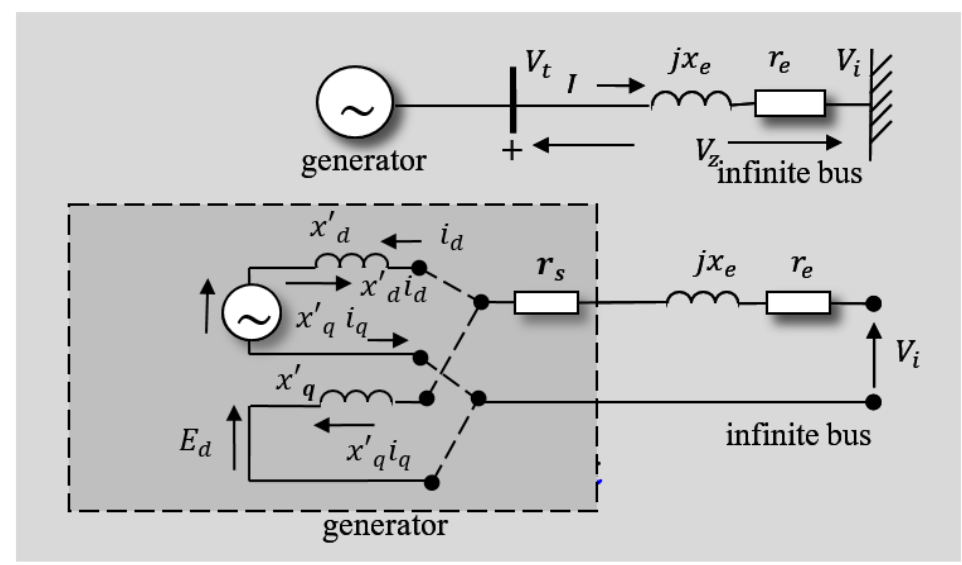

Figure 1. Single machine infinite bus system [23]

Table 1. Transient generator model with changes in stator $q d 0$ flux linkages neglected [23]

\begin{tabular}{cc}
\hline Object & Equation \\
\hline Stator winding & $v_{q}=-r_{s} i_{q}-x_{d}^{\prime} i_{d}+E_{q}^{\prime} v_{d}=-r_{s} i_{d}-x_{q}^{\prime} i_{q}+E_{d}^{\prime}$ \\
Rotor & $T_{d 0}^{\prime} \frac{d E_{q}^{\prime}}{d t}+E_{q}^{\prime}=E_{f}-\left(x_{d}-x_{d}^{\prime}\right) i_{d} \lambda_{q}^{\prime}=\lambda_{q}-L_{q}^{\prime}\left(-i_{q}\right) E_{d}^{\prime}=-\omega_{e} \lambda_{q}^{\prime}$ \\
winding & $T_{q 0}^{\prime} \frac{d E_{d}^{\prime}}{d t}+E_{d}^{\prime}=E_{g}-\left(x_{q}-x_{q}^{\prime}\right) i_{q} \lambda_{q}^{\prime}=\lambda_{q}-L_{q}^{\prime}\left(-i_{q}\right) E_{q}^{\prime}=-\omega_{e} \lambda_{d}^{\prime}$ \\
$\begin{array}{c}\text { Mechanical } \\
\text { torque }\end{array}$ & $T_{e m}=-\frac{3}{2} \frac{P}{2 \omega_{e}}\left\{E_{q}^{\prime} i_{q}+E_{d}^{\prime} i_{d}+\left(x_{q}^{\prime}-x_{d}^{\prime}\right) i_{d} i_{q}\right\}=-\left\{E_{q}^{\prime} i_{q}+E_{d}^{\prime} i_{d}+\left(x_{q}^{\prime}-x_{d}^{\prime}\right) i_{d} i_{q}\right\}$ \\
Rotor & $j \frac{d \omega_{r m}}{d t} T_{e m}+T_{\text {mech }}-T_{\text {damp }}=2 H \frac{d\left\{\left(\omega_{r}-\omega_{e}\right) / \omega_{b}\right\}}{d t} d \delta_{e} / d t=\omega_{r}-\omega_{e} \omega_{r}=(P / 2) \omega_{r m}$ \\
\hline
\end{tabular}

Taking slight displacement considering values of the steady state operating designated by and supplementary subscript $o$, we will get

$$
\begin{aligned}
& \Delta P_{e m}=\Delta i_{q}+i_{q o}\left(\Delta E_{q}^{\prime}+\left(x_{q}-x_{d}^{\prime}\right) \Delta i_{d}\right)=K_{1} \Delta \delta+K_{2} E_{q}^{\prime} \\
& T_{d o}^{\prime} \frac{d \Delta E_{q}^{\prime}}{d t}+\Delta E_{q}^{\prime} / K_{3}=\Delta E_{f}-K_{4} \Delta i_{d} \Delta V_{t}=K_{5} \Delta \delta+K_{6} \Delta E_{q}^{\prime}
\end{aligned}
$$

where

$$
\begin{aligned}
& K_{1}=\frac{E_{q} V_{i}}{D z}\left\{r_{e} \sin \delta_{o}+\left(x_{e}+x_{d}^{\prime}\right) \cos \delta_{o}\right\}+\frac{i_{q o}\left(x_{q}-x_{d}^{\prime}\right) V_{i}}{D z}\left\{\left(x_{e}+x_{q}\right) \sin \delta_{o}-r_{e} \cos \delta_{o}\right\}, \\
& K_{2}=\frac{E_{q o} r_{e}}{D z}+\frac{i_{q o}}{D z}\left\{1+\left(x_{q}-x_{d}^{\prime}\right)\left(x_{e}+x_{q}\right)\right\} K_{3}=\left\{1+\frac{\left(x_{d}-x_{d}^{\prime}\right)\left(x_{e}+x_{q}\right)}{D z}\right\}^{-1} \\
& K_{4}=\frac{V_{i}\left(x_{d}-x_{d}^{\prime}\right)}{D z}\left\{\left(x_{e}+x_{q}\right) \sin \delta_{o}-r_{e} \cos \delta_{o}\right\}, K_{6}=\frac{v_{q o}}{V_{t}}\left\{1-\frac{x_{d}^{\prime}\left(x_{e}+x_{q}\right)}{D z}\right\}+\frac{v_{d o}}{V_{t}} \frac{x_{q} r_{e}}{D z}, \\
& K_{5}=V_{i} \frac{v_{d o}}{V_{t}} \frac{x_{q}}{D z}\left\{r_{e} \sin \delta_{o}+\left(x_{e}+x_{d}^{\prime}\right) \cos \delta_{o}\right\}+V_{i} \frac{v_{d o}}{V_{t}} \frac{x_{d}^{\prime}}{D z}\left\{r_{e} \cos \delta_{o}-\left(x_{e}+x_{q} \sin \delta_{o}\right)\right\}
\end{aligned}
$$




\subsection{Power system stabilizer}

\subsubsection{Concept of power system stabilizer}

Heffron and Phillips [24] developed single machine connected to an external grid using an electromechanical model of a synchronous generator with an excitation system. Then, De Mello and Concordia [25] used such model to describe the electrical oscillations and damping torque in an electrical system, shown in Figure 2. In this figure, the contribution of torque created by the stabilizer path is given by:

$$
\frac{\Delta T_{E P}}{\Delta \varpi_{G}}=P S S_{\omega}(s) G E P(s) \triangleq P(s) G E P(s) \cong \frac{K_{2}}{K_{6}} \frac{\partial E_{t}}{\partial E_{\text {ref }}}\left|G E P\left(j \omega_{i}\right)\right| \cong K_{2} \frac{\left|\operatorname{Exc}\left(j \omega_{i}\right)\right|}{\omega_{i} T_{d o}^{\prime}}
$$

The $G E P(s)$ is a transfer function which defines the characteristics of the generator, the excitation system, and the power system, shown in Figure 3. The generators typically have a voltage regulator transient gain which results in satisfactory operation conditions. Slight phase lag of excitation system will relatively give high gain at small loads, but will intentionally reduce damping of rotor oscillations and may affect an instability.

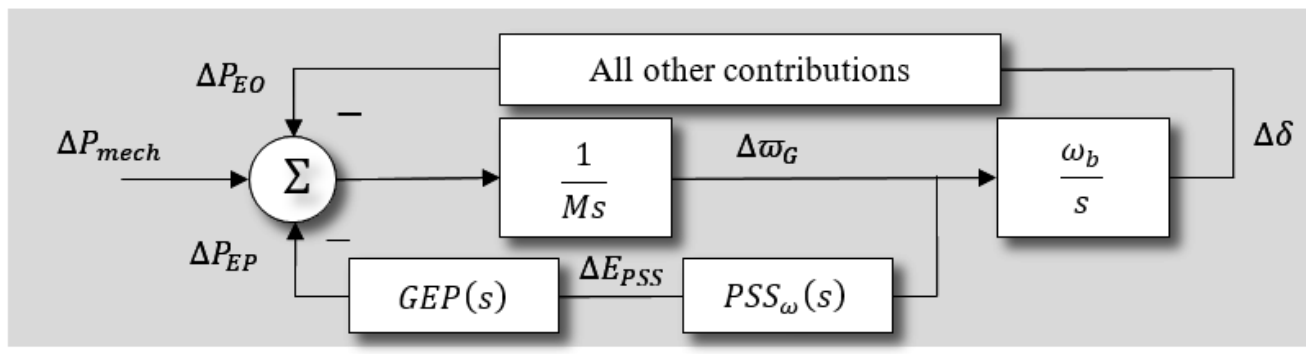

Figure 2. Block diagram of stabilizer with speed-input system [26]

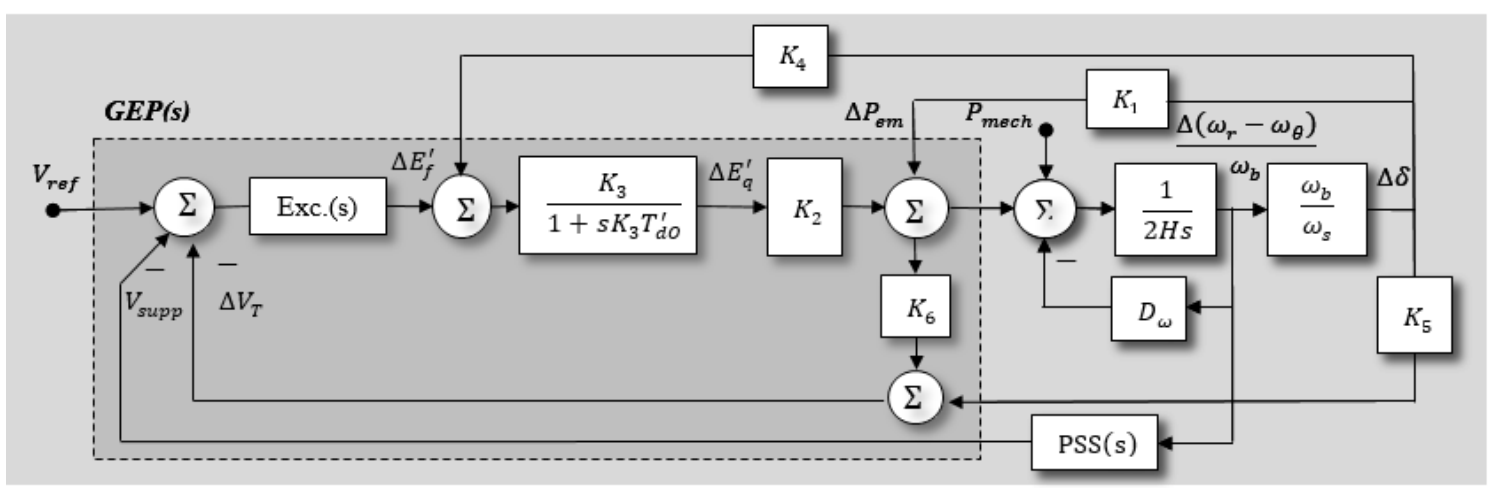

Figure 3. Transfer function blocks of synchronous generator with exciter and PSS using slip speed [27]

The value of $1 /\left(K_{3} T_{D 0}^{\prime}\right)$ is assumed less than the cross-over frequency. The gain is also proportional to the parameter $K_{2}$ which denotes the result of a change in generator flux $\left(E_{q}^{\prime}\right)$ on torque; consequently, it is increased with generator loading and also increased as the power system becomes stronger. Quite the reverse, for situations where the voltage regulator loop crossover frequency is greater than the oscillation frequency of concern, the gain of $G E P(s)$ is no longer proportional to regulator gain. It is inversely proportional to the parameter $K_{6}$, which decrease as the ac system becomes stronger and hence causes the gain of $G E P(s)$ to further increase as the power system strength increases.

\subsubsection{Structure of conventional power system stabilizer}

The conventional PSS consists of wash-out circuit, two stages of phase compensation, filter and limiter. A wash-out circuit is a high pass filter (HPF) for readjust action to remove steady-state offset, shown in Figure 4. The two stages of phase compensation which composed of two lead-lag compensators have center frequencies of compensation of $1 / 2 \pi \sqrt{T_{1} T_{2}}$ and $1 / 2 \pi \sqrt{T_{3} T_{4}}$. The lead stage is used to compensate 
for the phase lag introduced by the AVR and the field circuit of the generator. Meanwhile, a filter section is used to suppress frequency components in the input signal of PSS that could stimulate undesirable interaction and a limiter prevents the PSS's output signal from driving the excitation into saturation. The PSS's output signal is fed an adding input signal, $V_{\text {supp }}$, to the regulator of excitation system.

The AVR is to maintain the terminal voltage of generators because of adjusting the exciter voltage of the generators. AVR unit typically includes an error amplifier with limiters. The degree of transient gain reduction can be done using a compensator that has $T_{C}<T_{B}$. The stabilizer feedback signal, $V_{f}$, and supplementary signal, $V_{\text {supp }}$, are arrived at the input regulator from a PSS. The AVR's output must be increased by the exciter before it has the necessary power and range to excite the field winding of a large generator. The exciter consists of the field winding, magnetic nonlinearity of the exciter's main field path, and the armature. The voltage equation of the field winding and region of $S_{e}$ curve around the normal operation condition can be approach by an exponent function; its current and voltage as shown in (4). Figure 5 shows a block diagram of the transfer function between $v_{x}$ and $v_{f}$. The feedback gain is a function of $r_{f}$, but $\tau_{E}$ will not be affected by changes in $r_{f}$.

$$
i_{f p u}=v_{x p u}+R_{a g} S_{e}\left(i_{f}\right) v_{x p u} v_{f p u}=\left[K_{E}+\frac{r_{f}}{R_{a g}} S_{\text {epu }}\left(v_{x p u}\right)\right] v_{x p u}+\tau_{E} \frac{d v_{x p u}}{d t}
$$

where

$$
S_{\text {epu }}=\frac{i_{f p u}-v_{x p u} / R_{a g}}{v_{x p u} / R_{a g}}=\frac{A-B}{B}, \tau_{E}=\frac{d \lambda_{f}\left(v_{x}\right)}{d v_{x}}=\frac{d \lambda_{f}\left(v_{x p u}\right)}{d v_{x p u}}, K_{E}=\frac{r_{f}}{R_{a g}}, \text { and } S_{E}=\frac{r_{f}}{R_{a g}} S_{\text {epu }}\left(v_{x p u}\right)
$$

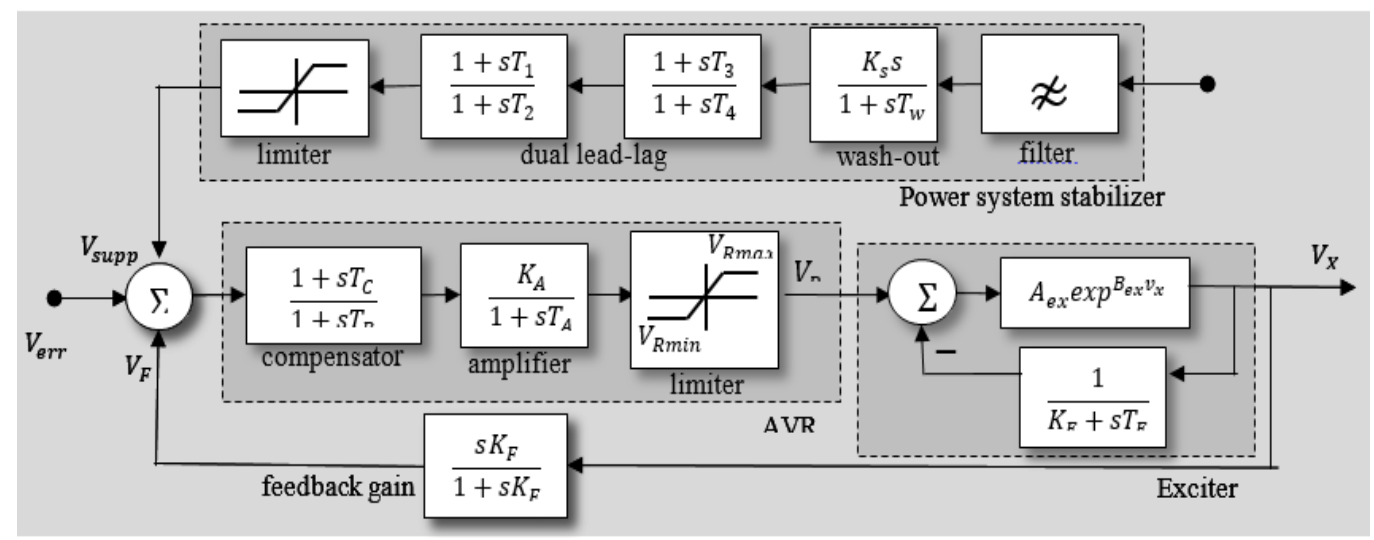

Figure 4. Power system stabilizer with AVR and exciter [28], [29]
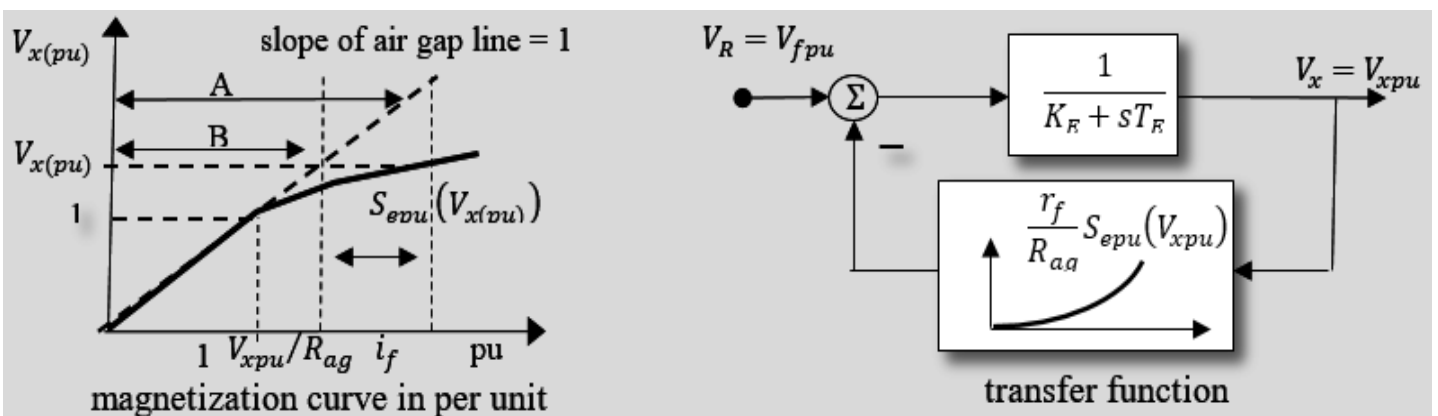

Figure 5. Magnetization curve and transfer function of exciter (in pu) [30]

\subsection{Auto-tuning stabilizer of PID structure}

Since conventional PSS consists of dual lead-lag compensator unit and its parameters are not tuning by original system parameter, so its control is less flexibility and the control results are far from ideal during drastic higher changing of its operation condition, such as am overshoot. One of many solutions to eliminate

Teaching power system stabilizer and proportional-integral-derivative impacts on ... (Sugiarto Kadiman) 
the overshoot in step response is applying an auto-tuning stabilizer of PID structure, shown in Figure 6. PID controller is a generic control loop feedback method that will correct the error between a measured process variable and the desired input by calculating and give an output of correction that will alter the process accordingly. A PID controller has the general form: $u(t)=K_{p} e(t)+K_{i} \int_{0}^{t} e(t) d t+K_{d} \frac{d e}{d t}$ where $K_{p}, K_{i}$, and $K_{d}$ are proportional, integral, and derivative gains, respectively. The calculation involves three separate parameters; the proportional, the integral and derivative values. The weighted sum of these three actions is used to adjust the process for obtaining the desired output. The tuning rule based on process reaction curve methods or Ziegler-Nichols's method [31],

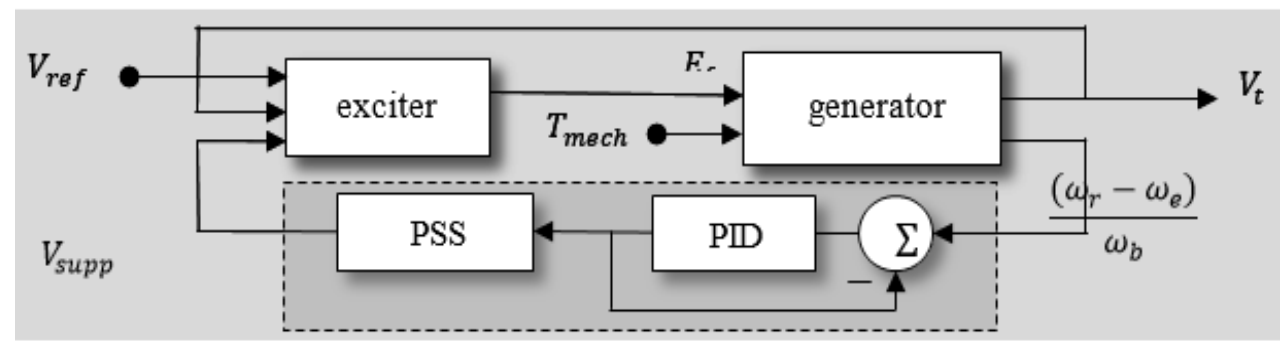

Figure 6. Block diagram of the proposed auto-tuning stabilizer of PID structure

\subsection{Simulator of auto-tuning stabilizer of PID on transient generator under MATLAB/Simulink}

A linearized model of synchronous generator unit is programmed shown in Figure 7, using basic Simulink model components. As shown, the inputs are the excitation command voltage, $E_{f}$, stator winding voltages, $V_{d e}$ and $V_{q e}$. The outputs are terminal voltage magnitude, $V$, terminal current, $I$, active and reactive powers at terminals, $P_{g e n}$ and $Q_{g e n}$, relative load angle, $\delta$, slip, $\left(\omega_{r}-\omega_{e}\right)$, and accelerating torque, $T_{e m}$.

In Figure 8, a model of an excitation system is shown. As shown, the inputs are the excitation command voltage, $V_{r e f}$, the supply voltage, $V_{\text {supp }}$, obtained from output of auto-tuning stabilizer of PID structure, and terminal voltage of generator, $V_{t}$. A model of an exciting system may be represented by the third order model. As shown, the voltage equation of the field winding and region of magnetization curve, $S_{e}$, around the normal operation condition can be approximate by an exponential function, $A_{\text {ex }} \exp ^{B_{e x} v_{x}}$.

A single-machine infinite bus system connected with exciter and auto-tuning stabilizer of PID structure can be easily constructed from the modules described in section 2, as shown in Figure 9. This can be accomplished by choosing specific number of generating unit and connecting them to an infinite bus. Once the auto-tuning stabilizer of PID structure is interfaced with the single-machine infinite bus system, an output of the network injects the exciter. And finally, the exciter will inject the transient generator.

We can access GUI facilities of MATLAB to compose a software package of simulator for studying the effects of PSS and PID on transient synchronous generator. The synchronous generator and conventional PSS parameters are shown in Table 2. As an example of using GUIDE, the MATLAB GUI development environment, abilities, menu and plotting commands are employed in a script file or $\mathrm{m}$-file to deliver interactive windows. These tools significantly reduce the process of designing and building GUIs. GUIDE automatically produces a MATLAB program file that controls how the GUI works [32].

Table 2. Generator, exciter, and PSS parameters

\begin{tabular}{ll}
\hline \multicolumn{1}{c}{ Unit } & \multicolumn{1}{c}{ Parameters } \\
\hline Generator & $V_{\text {rated }}=18 \mathrm{kV} P_{\text {rated }}=83 \mathrm{MW} r_{s}=0.0048 \mathrm{pu} x_{d}=1.790 \mathrm{pu}$ \\
& $x_{q}=1.660 \mathrm{pu} x_{l s}=0.215 \mathrm{pu} x_{d}^{\prime}=0.355 \mathrm{pu} x_{q}^{\prime}=0.570 \mathrm{pu}$ \\
& $x_{d=}^{\prime \prime}=0.275 \mathrm{pu} x_{q}^{\prime \prime}=0.275 \mathrm{pu} T_{d o}^{\prime}=7.9 \mathrm{pu} T_{q o}^{\prime}=0.410 \mathrm{pu}$ \\
& $T_{d o}^{\prime \prime}=0.032 \mathrm{pu} T_{q o}^{\prime \prime}=0.055 \mathrm{pu} H=3.77 \mathrm{pu} D_{\omega}=2 \mathrm{pu}$ \\
& $K A=50 \mathrm{pu} V_{i}=1.0+j 0.0 S_{i}=0.8+j 0.6$ \\
Infinite bus & $r_{e}+j x_{e}=0.027+\mathrm{j} 0.1$ (high inductance) $r_{e}+j x_{e}=0.013+\mathrm{j} 0.05$ (low inductance) \\
Exciter & $T A=0.06 V_{R \max }=1 \mathrm{pu} V_{R \min }=-1 \mathrm{pu}$ \\
& $T E=0.052 K E=-0.0465 \mathrm{pu} T F=1.0 \mathrm{pu}$ \\
PSS & $K F=0.0832 \mathrm{AEx}=0.0012 \mathrm{pu} B E x=1.264 \mathrm{pu}$ \\
& $K_{S}=120 T_{W}=1.0 T 1=0.024$ \\
PID Controller & $T 2=0.024 T 3=0.024 T 4=0.002$ \\
& $K_{p}=1.3 K_{i}=0.9 K_{d}=0.2$ \\
\hline
\end{tabular}


To perform different operations and to visualize the different dynamic performances we have fulfilled and established a GUI under MATLAB. This Interface permits as to improve human-computer interaction, present control system from conventional PSS, fast view of the system regulation results and simulation, compute the system dynamic parameters, and exploit of the different PID controller, shown in Figure 10 .

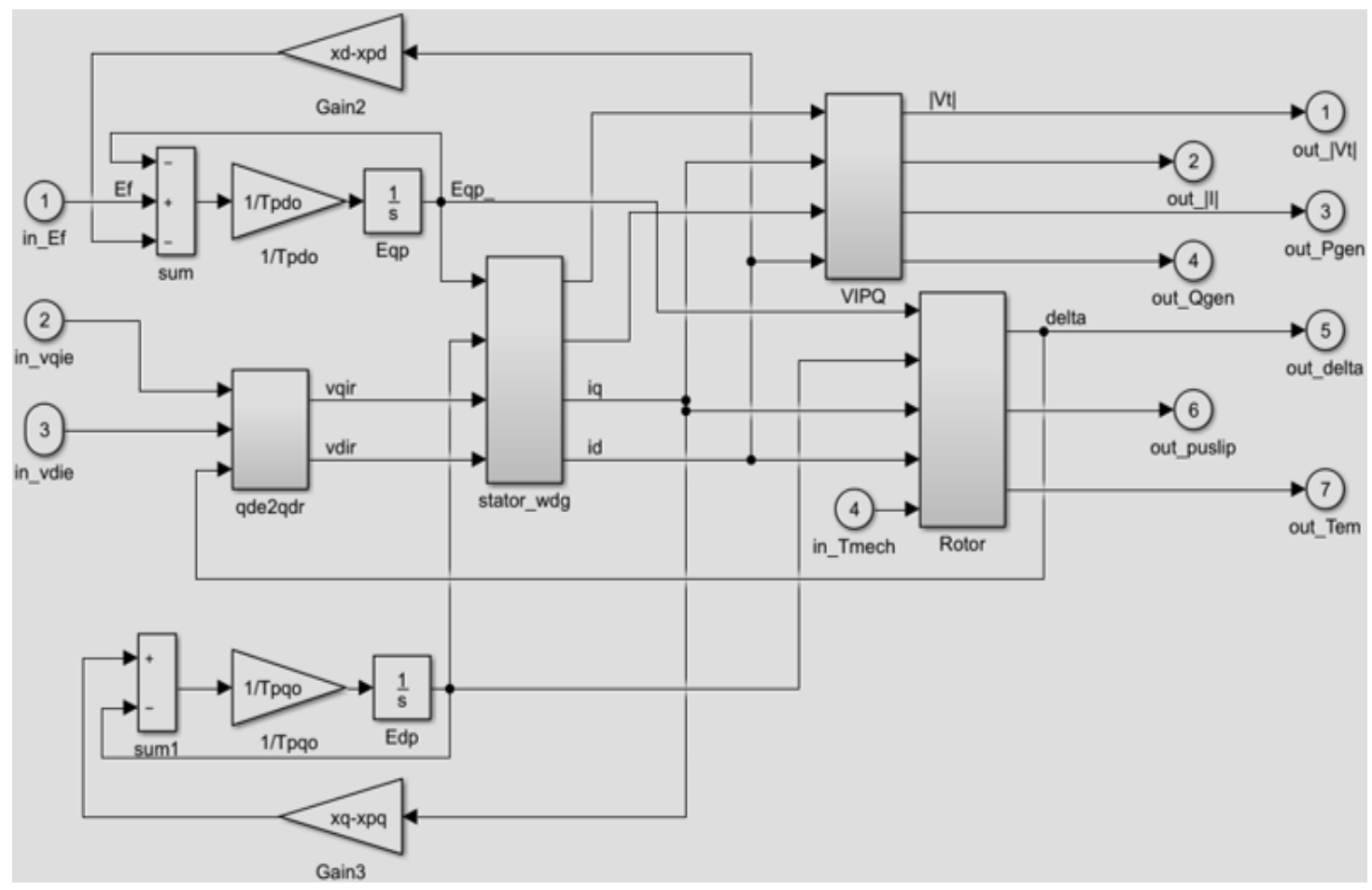

Figure 7. Simulink model diagram of linearized model of synchronous generator

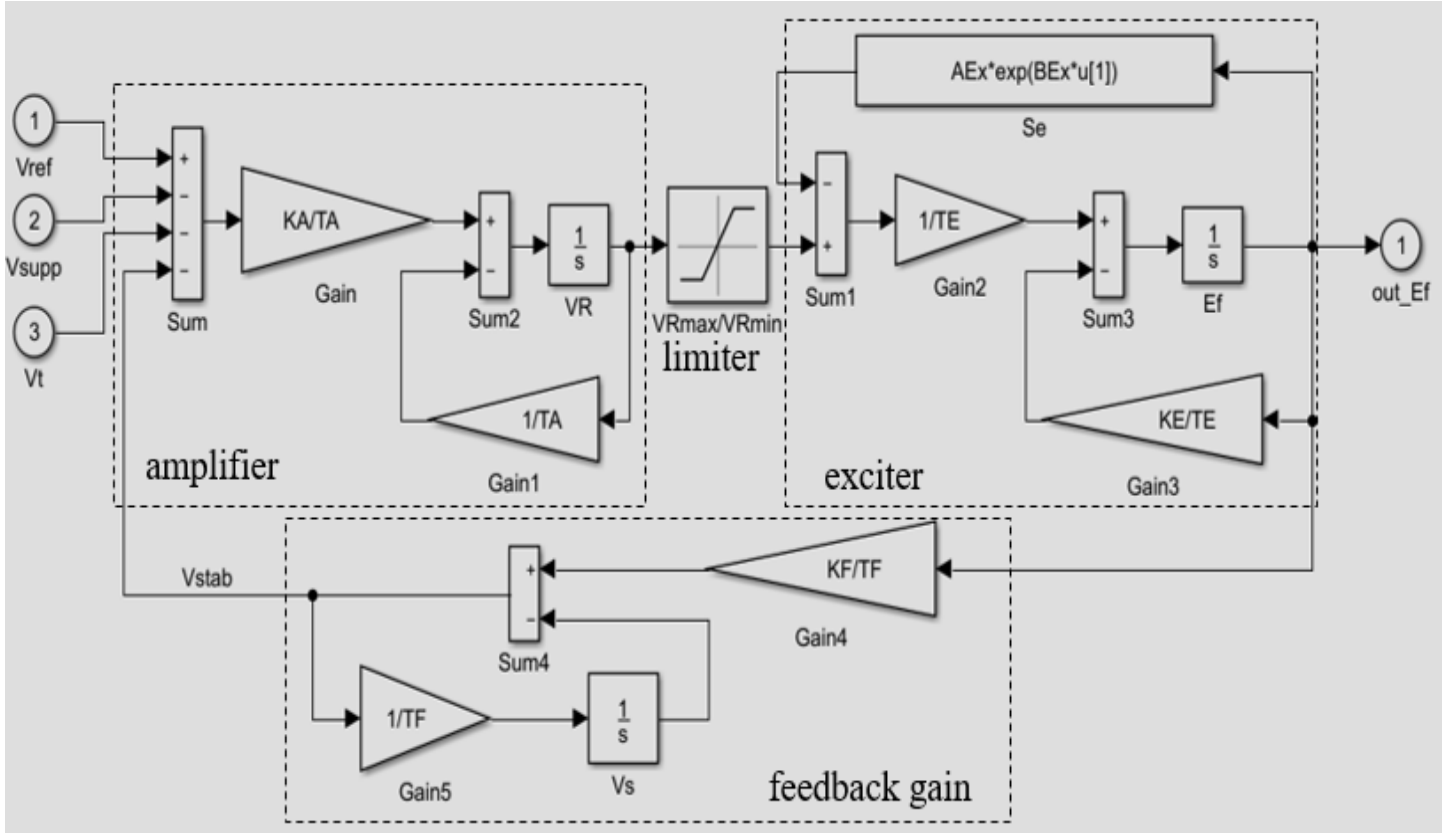

Figure 8. Simulink model diagram of exciting system 


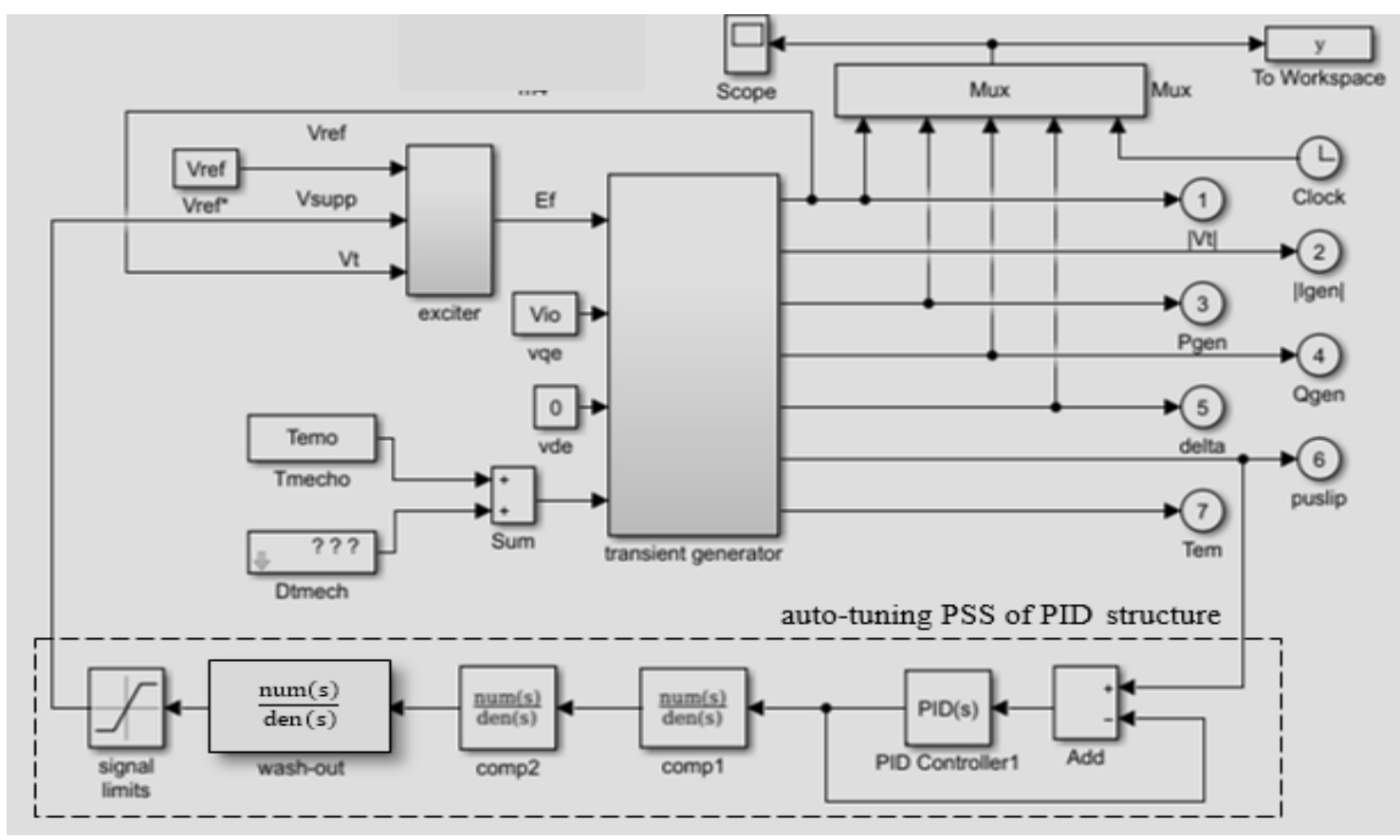

Figure 9. Simulink model diagram of generator connected with exciter and stabilizer of PID structure

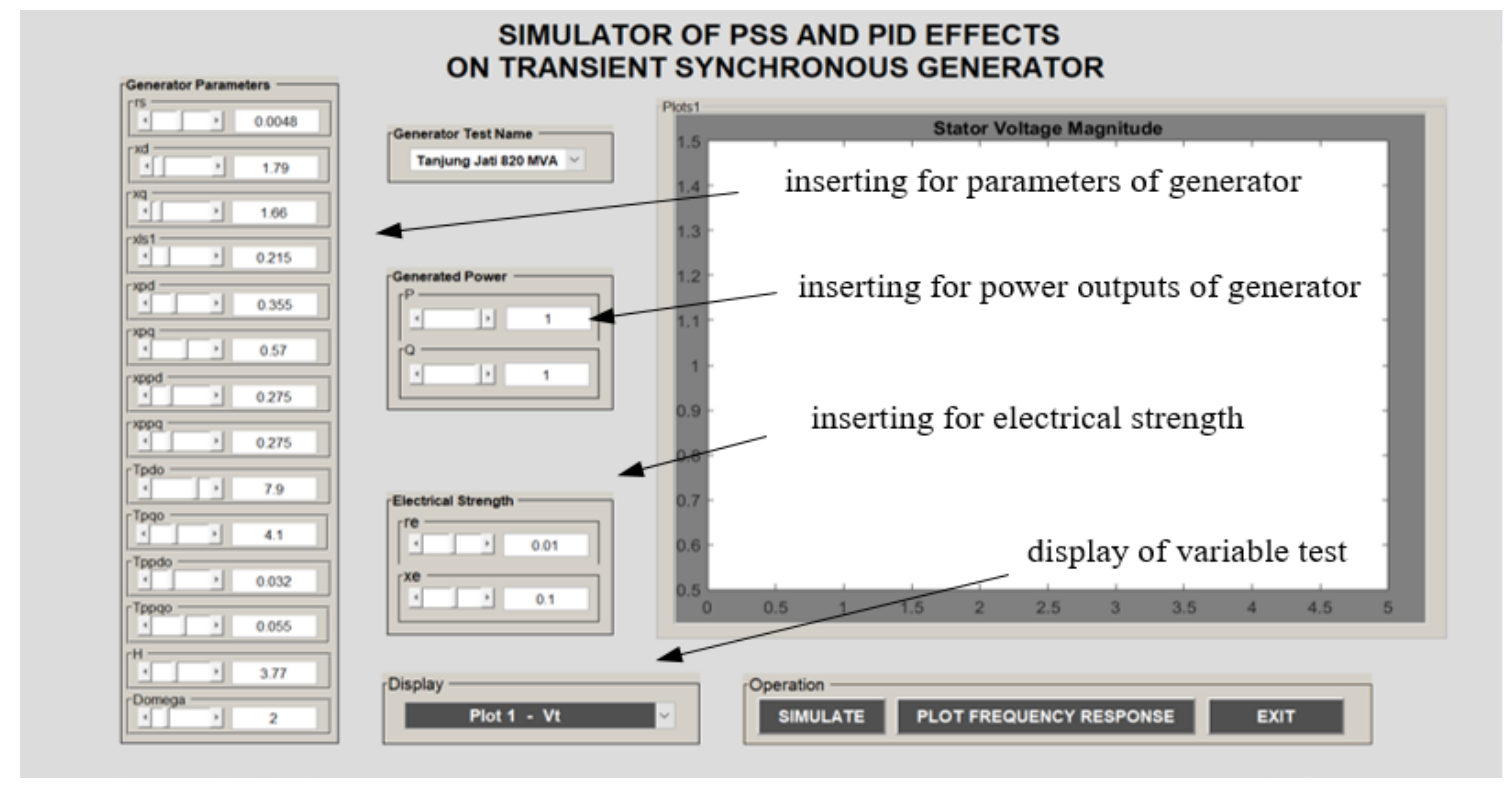

Figure 10. The window of inserting the inputs and displaying the variable assessments

\section{RESULTS AND ANALYSIS}

With the purpose of exploring the effect of auto-tuning stabilizer of PID Structure which comprise conventional PSS and PID controller, on transient synchronous generator, numeral simulations were carried out for several circumstances under different operating conditions, such as stable system and unstable system. The SMIB model is used and the values of delivered complex power $S_{i}$ and torque perturbation about operating point $T_{P}$ are subject to change in pu. Figure 11 (a) and 11 (b) show Bode plots of $G E P(s)$ with infinite buses of $r_{e}+j x_{e}=0.027+\mathrm{j} 0.1$ and $r_{e}+j x_{e}=0.013+\mathrm{j} 0.05$, respectively; While Figure 12 (a) and 12 (b) show Bode plots of PSS(s) with infinite buses of $r_{e}+j x_{e}=0.027+\mathrm{j} 0.1$ and $r_{e}+j x_{e}=0.013+\mathrm{j} 0.05$, respectively. The system operating points are at $S_{i}=0.8+j 0.6 \mathrm{pu}$ and $V_{t}=1.0 \mathrm{pu}$, shown in Table 2 . The gain of PSS(s) is DPSS=6. The phase plot of $G E P(s)$ has two poles near $6.5 \mathrm{~Hz}$ or $40.8 \mathrm{rad} / \mathrm{sec}$. From the 
phase plot of $\operatorname{PSS}(s)$, we can see that the desired phase characteristic of the PSS ought to be lagging below $40.8 \mathrm{rad} / \mathrm{sec}$ and leading above $40.8 \mathrm{rad} / \mathrm{sec}$. There is no difference between two figures over desired stabilization frequency range centered around oscillation freq. of $40.8 \mathrm{rad} / \mathrm{sec}$. The phase compensation can be designed using lag-lead and lead-lag units. The initial values of $T_{1}$ and $T_{3}$ are $1 / 40.8$ or 0.024 . And the values of $T_{2}$ of lead-lag unit and $T_{4}$ of lag-lead unit might be 0.02 and 0.24 , respectively.
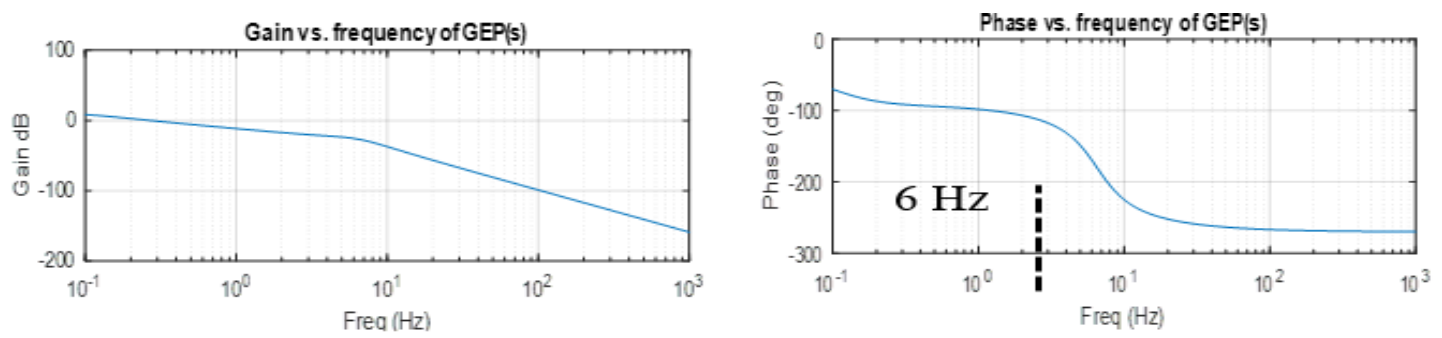

(a)
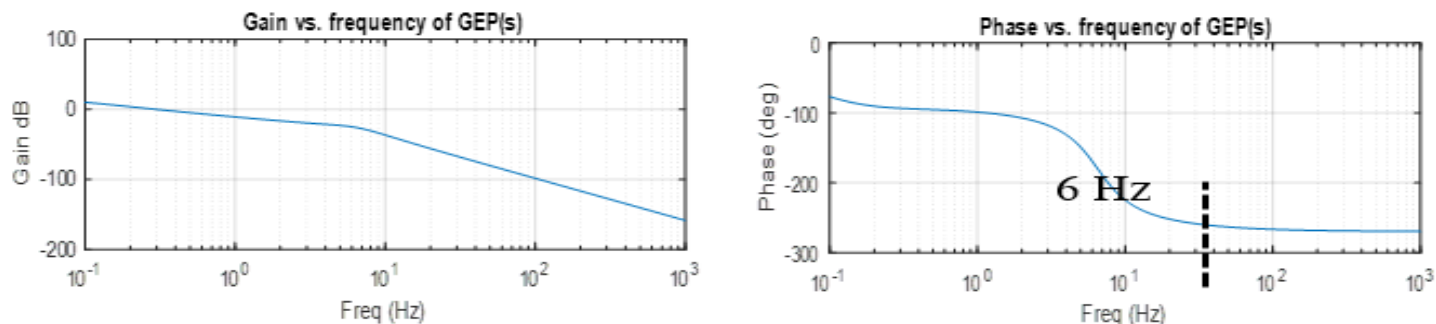

(b)

Figure 11. Bode plots of $G E P(s)$ in term of infinite bus's value, (a) infinite bus: $r_{e}+j x_{e}=0.027+j 0.1$, (b) infinite bus: $r_{e}+j x_{e}=0.013+j 0.05$
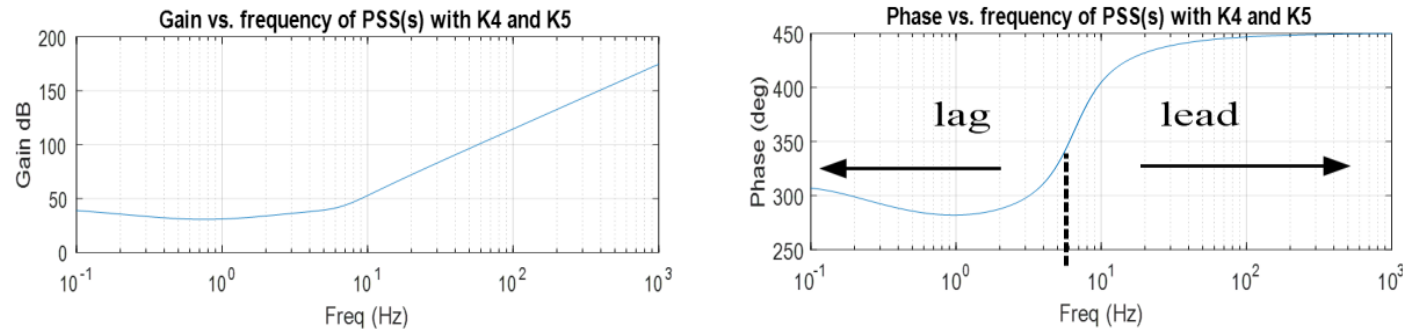

(a)
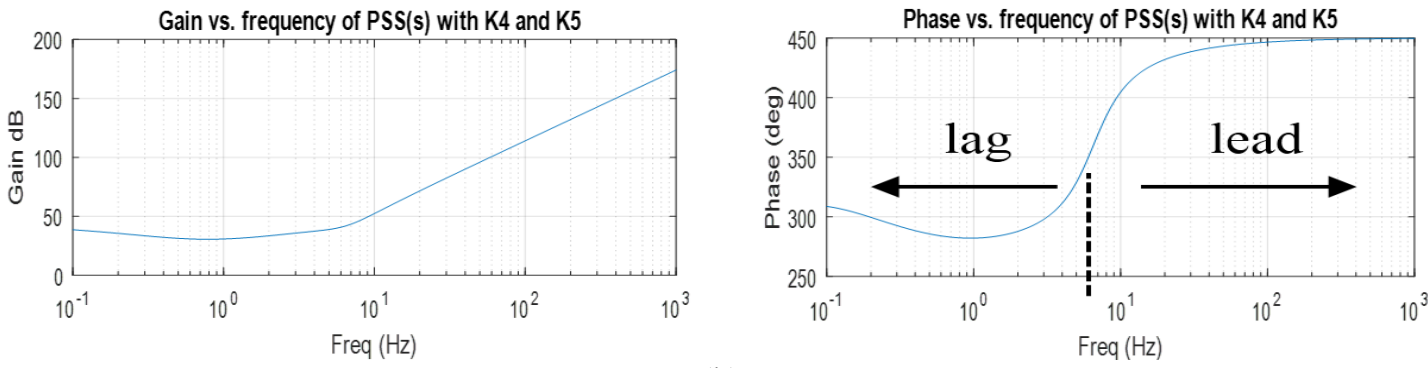

(b)

Figure 12. Bode plots of $P S S(s)$ in term of infinite bus's value, (a) infinite bus: $r_{e}+j x_{e}=0.027+j 0.1$, (b) infinite bus: $r_{e}+j x_{e}=0.013+j 0.05$

Figure 13, 14, and 15 show the plots of values of output voltage $\left|V_{t}\right|$, delta angle $\delta$, and active power $P_{G}$, respectively. As a result of a given value $K_{S}=120$ of wash-out network of PSS, the system response is stable on considerable perturbation, shown in those figures. When a LFO is appeared during unbalance

Teaching power system stabilizer and proportional-integral-derivative impacts on ... (Sugiarto Kadiman) 
between power demand and available power at a period of time, for example, the instability becomes apparent in the system simulation shown in Figure 13 (b), 14 (b), and 15 (b), where a given value of wash-out of PSS is $K_{s}=240$ or heavy perturbation. Definitely, the shape of output voltage of unstable system is not a straight line but slightly wavy, shown in Figure 13 (b). Comparing both delta angles in Figure 14 (a) and 14 (b), we can obtain significant difference; the shape of delta angle regarding the unstable system becomes out of under-damped response and has a big value of under-shoot, shown in Figure 14 (b). Figure 15 (a) shows a plot of active power's variable that has a slightly slower of steady state response comparing to its counterpart in Figure 15 (b).

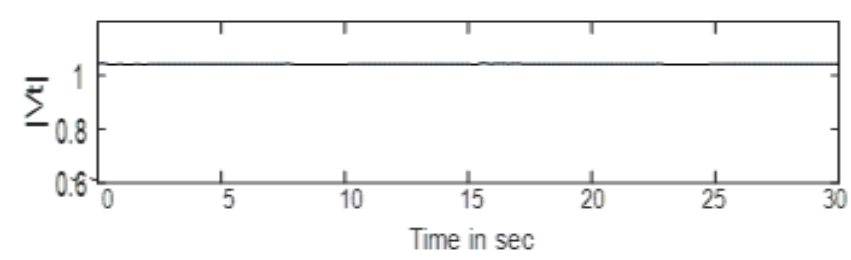

(a)

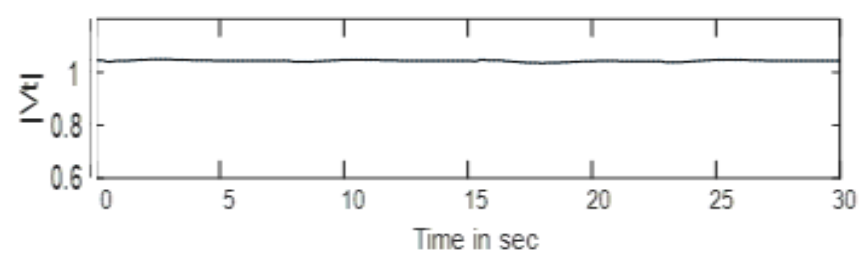

(b)

Figure 13. Bode plot of system responses in term of output voltage, (a) with considerable perturbation, (b) with heavy perturbation

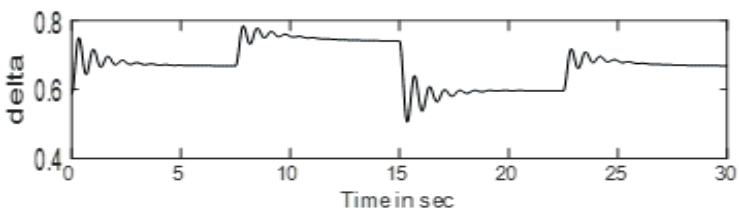

(a)

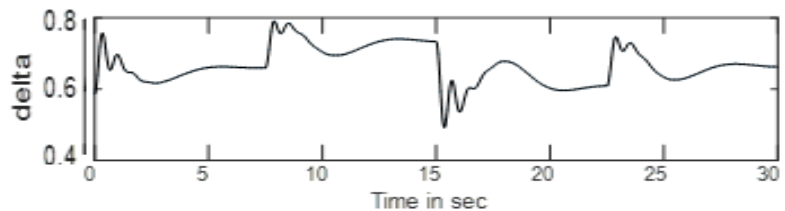

(b)

Figure 14. Bode plot of system responses in term of delta angle, (a) with considerable perturbation, (b) with heavy perturbation

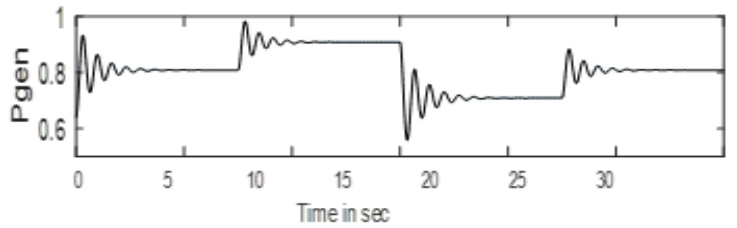

(a)

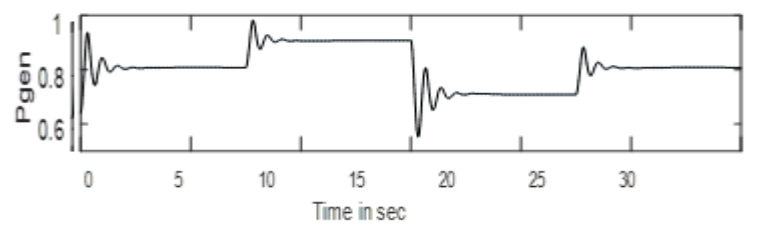

(b)

Figure 15. Bode plot of system responses in term of active power, (a) with considerable perturbation, (b) with heavy perturbation

Figure 16 (a) and 16 (b) illustrate the results of delta angles and active powers regarding system response after using conventional PSS and auto-tuning stabilizer during instability condition, respectively. The performance of auto-tuning stabilizer of PID structure is better than conventional PSS in term of respon system during a heavy perturbation, shown in Figure 16 (b); i.e, that eliminates both over-shoot and undershoot. 

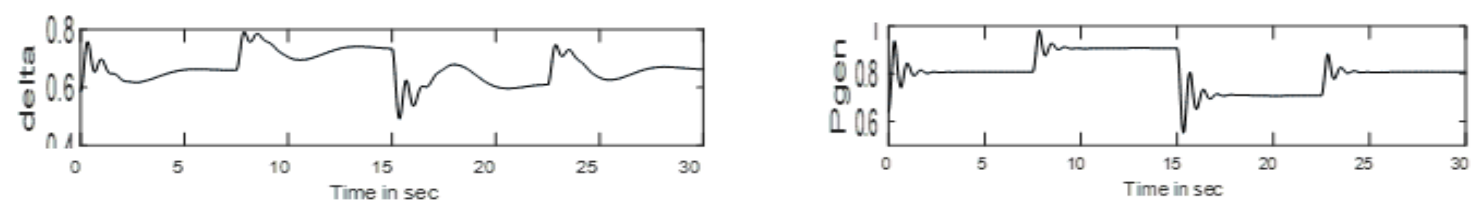

(a)
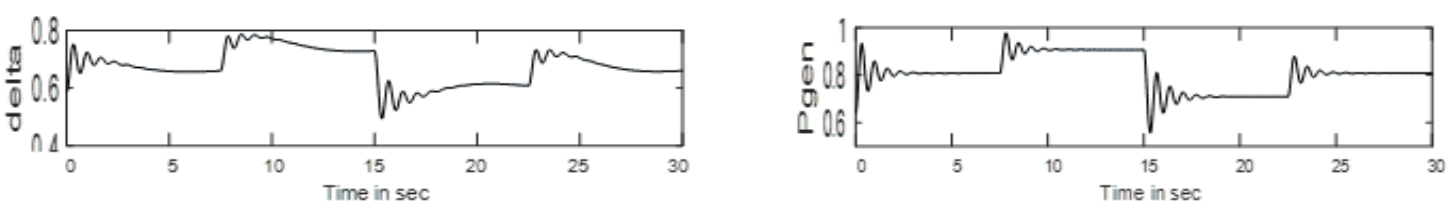

(b)

Figure 16. System respons of delta angle and active power during a heavy perturbation; (a) with conventional PSS during a heavy perturbation, (b) with auto-tuning PSS of PID structure during a heavy perturbation

\section{CONCLUSION}

In this study, an auto-tuning conventional PSS of PID structure is additional controller to damped low frequency oscillation and to improve dynamic performance of the generating unit. The use of combination between conventional PSS and PID controller to study power system stability concepts regarding transient synchronous generator working at various operating conditions is investigated. Results from this study indicate that auto-tuning PSS of PID structure gives much better dynamic performance as compare to that of conventional PSS. To use a PID controller tuned by Ziegler-Nichols's method will preserve the stability margin. Modeling of proposed auto-tuning stabilizer in Simulink environment provides an accurate result when compared to mathematical design approach. This experiment provided students of the electrical engineering study program with some realistic and challenging design experience and exposed them to a well-known power system stability problem regarding transient synchronous generator and its enhancement. The course survey indicated that the students were generally pleased with the design activities. Any one of the PSS design projects can be implemented for use with modifications of similar courses. A calculate algorithm can be added to obtain quantitative values regarding system response in term of a simple criteria. For a higher-level course, a PSS design for multiple-machine systems or the dual-input PSS design can be addressed. In addition, PSS designs for systems with multiple operating conditions can be counted.

\section{ACKNOWLEDGEMENTS}

The authors are thankful to Rector and Head of LPPMI, Institut Teknologi Nasional Yogyakarta for subsidy this project no. 11/ITNY/LPPMI/Pen.int/PD/II/2020. And also, to the Dean of Industrial Technology Faculty and the Head of Electrical Engineering Study Program, Institut Teknologi Nasional Yogyakarta for providing requirement services.

\section{REFERENCES}

[1] A. Hinda and M. Khiat, "Real-Time simulation of static synchronous condenser for compensation of reactive power," Indonesian Journal of Electrical Engineering and Computer (IJEECS), vol. 10, no. 6, pp. 5599-5608, December 2020, doi: 10.11591/ijece.v10i6.pp5599-5608.

[2] G. Deb and K. Chakraborty, "Gauss-Seidel Method based Voltage Security Analysis of Distribution System," International Journal of Electrical and Computer Engineering (IJECE), vol. 8, no. 1, pp. 43-51, February 2018, doi: 10.11591/ijece.v8i1.pp43-51.

[3] M. Jannati, T. Sutikno, N. R. N. Idris, and J. A. Aziz, "Modeling of Balanced and Unbalanced Three-Phase Induction Motor under Balanced and Unbalanced Supply Based on Winding Function Method," International Journal of Electrical and Computer Engineering (IJECE), vol. 5, no. 4, pp. 644-655, August 2015, doi: 10.11591/ijece.v5i4.pp644-655.

[4] E. P Madruga, D. P. Bernardon, R. P. Vieira, and L. L. Pfitscher, "Analysis of transient stability in distribution systems with distributed generation," Electric Power and Energy Systems, vol 99, pp. 555-565, 2018, doi: 10.1016/j.ijepes.2018.01.039.

[5] M. Saranya, A. Rajapandiyan, K. Fathima, S. Hema, S. G. Priya, and S. Saravanan, "A Power System Stabilizer for Multi Machine-Based on Hybrid BF0A-PSO," Indonesian Journal of Electrical Engineering and Computer Science (IJEECS), vol. 5, no. 2, pp. 213-220, 2015, doi: 10.11591/ijece.v5i2.pp213-220. 
[6] A. Tripathi, U. Rao, and L. R. Venkatesha, "Multi-Machine Stability Using Dynamic Inversion Technique," International Journal of Electrical and Computer Engineering (IJECE), vol. 7, no. 6, pp. 3176-3189, December 2017, doi: 10.11591/ijece.v7i6.pp3176-3189.

[7] G. Guralla and I. Sen," Power System Stabilizers Design for Interconnected Power Systems," IEEE Transactions on Power Systems, vol. 25, no. 2, pp. 1042-1051, May 2010.

[8] A. Mengistu and G. Kahsay, "The effect of computer simulation used as a teaching aid in students' understanding in learning the concepts of electric fields and electric forces," Latin-American Journal of Physics Education, vol. 9, no. 2, p. 3, June 2015 .

[9] S. M. Bagher Sadati, M. Yazdani-Asrami, M. Shafie-khah, G. J. Osório and J. P. S. Catalão, "Investigation of Distribution Transformer Loss of Life in Electric Vehicles Parking Lot Integrated System," 2020 IEEE 14th International Conference on Compatibility, Power Electronics and Power Engineering (CPE-POWERENG), 2020, pp. 230-235, doi: 10.1109/CPE-POWERENG48600.2020.9161684.

[10] C. Venugopal and T. Govender, "Load power and energy management system using proteus visual design software," Indonesian Journal of Electrical Engineering and Computer Science (IJEECS), vol. 20, no. 2, pp. 10441052, November 2020, doi: 10.11591/ijeecs.v20.i2.pp1044-1052.

[11] D. Butti, K. Mangipudi, and S. R. Rayapudi, "An improved whale optimization algorithm for the design of multimachine power system stabilizer," International Transaction on Electrical Energy Systems, vol. 30, no. 5, p. e12314, 20 January 2020, doi: 10.1002/2050-7038.12314.

[12] O. M. Neda," Optimal coordinated design of PSS and UPFC-POD using DEO algorithm to enhance damping performance," International Journal of Electrical and Computer Engineering (IJECE), vol. 10, no. 6, pp. 61116121, December 2020, doi: 10.11591/ijece.v10i6.pp6111-6121.

[13] K. Wahiba, G. D. Eddine, and N. Abdellatid, "An Advanced Robust AVR-PSS Based H2 and Ho Frequency Approach Simulated Under a Realized GUI," International Journal of Power Electronics and Drive Systems (IJPEDS), vol. 15, no. 3, pp. 468-477, Sep. 2015, doi: 10.11591/ijpeds.v6i2.7331.

[14] S. Gomes Jr, C. H. C. Guimaraesm N. Martins, and G. N. Taranto, "Damped Nyquist Plot for a pole placement design of power system stabilizers," Electric Power System Research, vol. 158, pp. 158-169, May 2018, doi: 10.1016/j.epsr.2018.01.012.

[15] A Khosravi and M. Y. Asrami, "Application of swarm-based optimization algorithms for solving dynamic economic load dispatch problem," Journal of Advances in Computer Research, vol. 6, no. 4, pp. 13-26, 2015.

[16] MM Linda and K. Nair, "Optimal Design of Fuzzy Based Power System Stabilizer Self Tuned by Robust Search Algorithm," Journal of Computing, vol. 1, no. 1, December 2009.

[17] D. Acharya, D. K. Das and A. Rai, "Particle Swarm Optimization (PSO) based 2-DoF-PID power system stabilizer design for damping out low frequency oscillations in power systems," 2019 2nd International Conference on Innovations in Electronics, Signal Processing and Communication (IESC), 2019, pp. 148-153, doi: 10.1109/IESPC.2019.8902378.

[18] I. B. G. Manuaba, M. Abdillah, A. Priyadi, and M. H. Purnomo, "Coordinated Tuning of PID based PSS and AVR Using bacterial Foraging PSOTVAC-DE Algorithm," Control and Intelligent System, vol. 43, no. 3, pp. 1480-1752, Nov. 2015, doi: 10.2316/Journal.201.2015.3.201-2399.

[19] K. C. Sio and C. K. Lee, "Stability of fuzzy PID controllers," in IEEE Transactions on Systems, Man, and Cybernetics - Part A: Systems and Humans, vol. 28, no. 4, pp. 490-495, July 1998, doi: 10.1109/3468.686710.

[20] I. Pan, S. Das, and A. Gupta, "Tuning of an optimal fuzzy PID controller with stochastic algorithms for networked control systems with random time delay," ISA Transactions, vol. 50, no. 1, pp. 28-36, Jan. 2011, doi: 10.1016/j.isatra.2010.10.005.

[21] J. Cvejn, "Simple PI/PID Controller Tuning Rules for FOPDT Plants with Guaranteed Closed-Loop Stability Margin”, Acta Montanistica Slovaca, vol. 16, no. 1, pp. 17-25, 2011.

[22] J. Machowski, Z. Lubosny, J. W. Bialek, and J. R. Bumby, "Power System Dynamics: Stability and Control," John Wiley \& Sons, Ltd.: Sussex, UK 2008.

[23] P. C. Krause, O. Wasynczuk, and S. D. Sudhoff, "Analysis Electric Machinery and Drive System," Second Edition, IEEE Press. Piscataway, New Jersey, 1995.

[24] L. Zhao-wei, H. Yu-qiang, C. Xiao-dan, L. Wei and L. Bijun, "Parameters optimization of excitation system based on extended Heffron-Philips model," 2014 IEEE PES Asia-Pacific Power and Energy Engineering Conference (APPEEC), 2014, pp. 1-6, doi: 10.1109/APPEEC.2014.7066022.

[25] M. Balasubbareddy, G. Murthy, and K. S. Kumar, "Performance evaluation of different structures of power system stabilizers," International Journal of Electrical and Computer Engineering (IJECE), vol. 11, no. 1, pp. 114-123, February 2021, doi: 10.11591/ijece.v11i1.pp114-123.

[26] E. V. Larsen and D. A. Swann, "Applying Power System Stabilizers Part I: General Concepts," in IEEE Transactions on Power Apparatus and Systems, vol. PAS-100, no. 6, pp. 3017-3024, June 1981, doi: 10.1109/TPAS.1981.316355.

[27] E. V. Larsen and D. A. Swann, "Applying Power System Stabilizers Part III: Practical Considerations," in IEEE Transactions on Power Apparatus and Systems, vol. PAS-100, no. 6, pp. 3034-3046, June 1981, doi: 10.1109/TPAS.1981.316411.

[28] IEEE Standards Board, "IEEE Rec. Practice for Excitation System Models for Power System Stability Studies," IEEE Standard 42.5-1981, pp. 494-509, 1981doi: 10.1109/ieeestd.1992.106975.

[29] J. Li, "Design and Application of Modern Synchronous Generator Excitation Systems," Wiley, pp. 99-133, 2019.

Bulletin of Electr Eng \& Inf, Vol. 10, No. 4, August 2021 : 2383 - 2395 
[30] C. M. Ong, "Dynamic Simulation of Electric Machinery Using MATLAB/Simulink," P. Hall, N.J., pp. 463-490, 1998

[31] A. Dwyer, "PI and PID Controller Tuning Rules, $2^{\text {nd }}$ Ed.," Imperial College Press, LondonWC2H9HE, pp. 1-27, 2006.

[32] G. D. Eddine, N. Abdellatif, A. Mohamed, and K. Wahiba, "A Developed Graphical User Interface for Power System Stability and Robustness Studies," TELKOMNIKA Indonesian Journal of Electrical Engineering, vol. 15, no. 3, pp. 458-467, Sep. 2015, doi: 10.11591/ijeecs.v15.i3.pp458-467.

\section{BIOGRAPHIES OF AUTHORS}

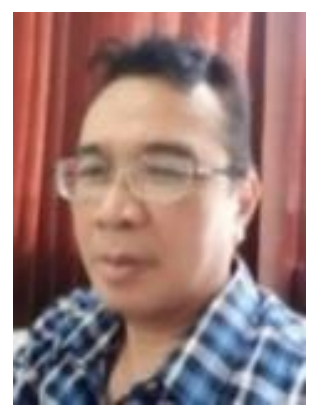

Sugiarto Kadiman received the Bachelor degree, Master degree, and Doctor degree in Electrical Engineering from Gadjah Mada University, Yogyakarta, Indonesia, in 1989, 2000, and 2014, respectively. Since 1990, he is working as Assistant Professor in the Program Study of Electrical Engineering, Institut Teknologi Nasional Yogyakarta, Indonesia. His research interest is model of Power System Analysis and Artificial Intelligent Systems.

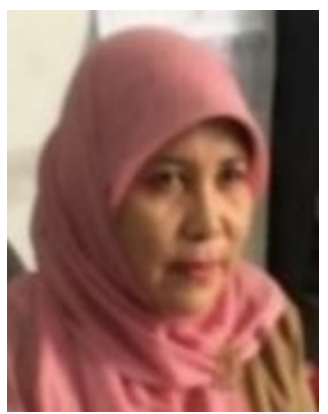

Oni Yuliani received the Bachelor degree in Electrical Engineering from Sriwijaya University, Palembang, Indonesia, in 1996. She received Master degree in Computer Science from Gadjah Mada University, Yogyakarta, Indonesia in 2006. Since 1994, she is working as Senior Lecturer in the Department of Electrical Engineering, Institut Teknologi Nasional Yogyakarta, Indonesia. Her research interest includes Computer Algorithm, and Probability and Stocastic Process.

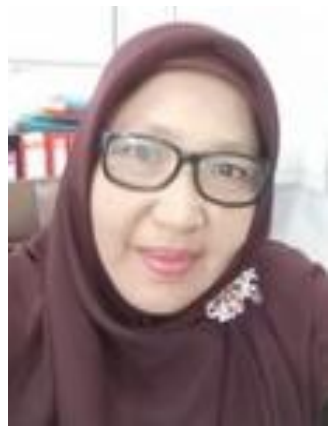

Trie Handayani received the Bachelor degree in Electrical Engineering from Sekolah Tinggi Teknologi Nasional, Yogyakarta, Indonesia, in 1997. She received Master degree in Computer Management from STMIK Amikom, Yogyakarta, Indonesia in 2013. Since 1999, she is working as Senior Lecturer in the Department of Electrical Engineering, Institut Teknologi Nasional Yogyakarta, Indonesia. Telecommunication and Computer Programming are her research interests. 